\title{
Cerebroplacental ratio in prediction of adverse perinatal outcome and fetal heart rate disturbances in uncomplicated pregnancy at 40 weeks and beyond
}

\author{
Mariola Ropacka-Lesiak ${ }^{1}$, Tomasz Korbelak², Joanna Świder-Musielak ${ }^{1}$, Grzegorz Breborowicz ${ }^{1}$
}

${ }^{1}$ Department of Perinatology and Gynecology, Poznan University of Medical Sciences, Poznan, Poland

2Obstetric Ward, Regional Hospital, Zary, Poland

Submitted: 20 October 2012

Accepted: 20 December 2012

Arch Med Sci 2015; 11, 1: 142-148

DOI: 10.5114/aoms.2015.49204

Copyright @ 2015 Termedia \& Banach

\section{Abstract}

Introduction: The aim of the study was to determine the usefulness of Doppler velocimetry, based on cerebroplacental ratio $(\mathrm{C} / \mathrm{U})$ evaluation, in predicting intrapartum fetal heart rate abnormalities and adverse neonatal outcome in uncomplicated pregnancies at 40 weeks and beyond.

Material and methods: One hundred and forty-eight women in uncomplicated pregnancies, between 40 and 42 completed weeks, were divided into control and study groups: with the absence $(n=79)$ and with the presence of a fetal brain-sparing effect $(n=69)$, respectively. Pulsatility and resistance indices in the middle cerebral, the umbilical artery and the $C / U$ ratio were evaluated daily by Doppler ultrasonography. $C / U<1.1$ was reported as suggestive of a brain-sparing effect. Abnormal flow indices were analyzed and compared to adverse pregnancy and neonatal outcome determinants.

Results: In the abnormal C/U group the abnormal CTG records were significantly more frequently observed $(62.3 \%)$ than in normal C/U group $(19.0 \%)$ $(p=0.0001)$. The comparison of selected Doppler indices revealed that $\mathrm{C} / \mathrm{U}$ showed the highest sensitivity in prediction of both the intrapartum abnormal FHR (74.1\%) and the adverse neonatal outcome (87.8\%).

Conclusions: The $\mathrm{C} / \mathrm{U}$ index shows the highest sensitivity in prediction of FHR abnormalities and adverse neonatal outcome in uncomplicated pregnancies at 40 weeks and beyond. The $\mathrm{C} / \mathrm{U}$ index is useful in clinical practice in antenatal monitoring of these women in order to select those at high risk of intra- and postpartum complications.

Key words: brain-sparing effect, perinatal outcome, term pregnancy, Doppler study.

\section{Introduction}

Fetal hypoxia is one of the major causes of high perinatal morbidity and mortality rates [1-3]. It may lead to various neurodevelopmental disabilities, ranging from difficulties in school to dyslexia, attention deficit hyperactivity disorder (ADHD), vision or hearing impairment, and mental disorders, including cerebral palsy [4, 5]. Fetal hypoxia activates a number of defense mechanisms, such as modification of fetal heart rate (FHR), increase in blood pressure and redistribution of blood to the heart, brain, and adrenal glands. Low oxygen partial pressure $\left(\mathrm{pO}_{2}\right)$ leads to cerebral vasodilation and a fall in vascular resistance, which results in a decrease

\author{
Corresponding author: \\ Mariola Ropacka-Lesiak \\ Department of Perinatology \\ and Gynecology \\ Poznan University \\ of Medical Sciences \\ 12 Teczowa St \\ 60-275 Poznan, Poland \\ Phone: +48 601765336 \\ E-mail: mariolaropacka@ \\ poczta.onet.pl
}


in middle cerebral artery resistance index (MCA RI) values.

Doppler ultrasound tests such as C/U evaluation are commonly used nowadays, and enable one to assess blood flow disturbances in placento-umbilical and feto-cerebral circulations [6]. The $\mathrm{C} / \mathrm{U}$ evaluation is used to detect and assess the fetal response to oxygen deficiency in utero. With the progress of pregnancy, the resistance in fetal circulation decreases gradually. Nevertheless, the values of MCA RI should remain higher than umbilical artery resistance ratio (UA RI) values, which implicates that $\mathrm{C} / \mathrm{U}$, being the ratio of MCA $\mathrm{RI}$ to UA RI, should be higher than 1-1.1 in uncomplicated pregnancies [7]. Animal experiments revealed high diagnostic value of $C / U$ in the detection of fetal circulatory redistribution, also known as the brain-sparing effect (BS). The values of the index decreased proportionally to the reduction of $\mathrm{pO}_{2}$ in the blood. Moreover, when fetal hypoxia occurred, $\mathrm{C} / \mathrm{U}$ showed better correlation with $\mathrm{pO}_{2}$ reduction than MCA RI.

The BS phenomenon is considered as an adaptive mechanism of the fetus which is activated to protect the fetal brain in adverse conditions. Despite the diverse and often controversial results concerning the assessment of the newborn, long-term evaluation of children with BS in utero showed that the phenomenon does not completely protect the brain against the effects of hemodynamic changes. Long-term studies have shown that children with BS have lower IQ scores, impaired cognitive function, attention deficit, and greater difficulties at school [8].

Therefore, the aim of the study was to assess the usefulness of $C / U$ in prediction of the intrapartum FHR abnormalities and the adverse perinatal outcome in uncomplicated pregnancies at 40 weeks and beyond.

\section{Material and methods}

\section{Study population and ethics}

The study was conducted at the Department of Perinatology and Gynecology from 2007 to 2009 and was approved by the medical ethics review board of the university. Gestational age ranged between 40 and 42 completed weeks of gestation. Patients' age ranged from 17 to 45 years. Fetal age was confirmed by ultrasound examination in the first trimester. As the study continued, 69 (46.62\%) eligible patients who met the criteria of fetal circulatory centralization constituted the study group, while the control group consisted of 79 patients with no signs of blood flow redistribution. In total, the research covered 148 patients in the course of uncomplicated pregnancy (a low risk group without any coexisting chronic diseases). All women were informed about the purpose of the study and the methods of examination. Consequently, informed consent was obtained from each patient.

\section{Clinical examination}

Doppler examination was carried out using a GE Logiq 5 PRO ultrasound machine (General Electric Healthcare, Europe) equipped with a variable frequency transducer 3.5 and $5.0 \mathrm{MHz}$, with pulsed wave Doppler option, also enabling real-time and color-coded imaging. The Doppler studies were performed in UA and MCA and characterized by two parameters: the pulsatility index $(\mathrm{PI})$ and the resistance index (RI). The study was performed by calculating the daily RI, PI, and C/U. The analysis covered the last result before birth.

The BS was diagnosed based on $C / U$ ratio assessment. According to Arbeille, $\mathrm{C} / \mathrm{U}$ is defined as the quotient of MCA RI and UA RI (C/U = MCA RI/UA RI) [7]. Values below 1.1 were reported as abnormal.

The FHR was monitored daily for at least $40 \mathrm{~min}$ using cardiotocography (CTG), and, additionally, continuous CTG monitoring was applied at delivery. The following exponents of abnormal FHR pattern, obtained from the latest intrapartum evaluation, were included in the analysis: 1) late and variable decelerations (at least three decelerations within $30 \mathrm{~min}$ ), 2) narrow or silent oscillations (lasting $40 \mathrm{~min}$ or longer), 3) baseline FHR below 110 or above 150 beats/min with the duration of at least $10 \mathrm{~min}$, according to FIGO 1987 recommendations [9].

Moreover, the following parameters were analyzed: maternal age, obstetric history, gestational age at delivery, umbilical cord blood $\mathrm{pH}$, base excess $(\mathrm{BE}), \mathrm{pO}_{2}$, carbon dioxide partial pressure $\left(\mathrm{pCO}_{2}\right)$, mean birth weight and prevalence of adverse perinatal outcome, and meconium-stained amniotic fluid (MSAF). Subsequently, the mode of delivery in the aspect of caesarean section occurrence was assessed, and special attention was paid to fetal distress as an indicator for cesarean section. The values reported as abnormal were: $\mathrm{pH}<7.20, \mathrm{BE}<-12 \mathrm{mEq} / \mathrm{l}, \mathrm{pO}_{2}<15 \mathrm{~mm} \mathrm{Hg}, \mathrm{pCO}_{2}$ $>45 \mathrm{~mm} \mathrm{Hg}$. The newborn's condition was considered adverse when at least one of the listed criteria was found: 5-minute Apgar score < 7, UA $\mathrm{pH}<7.20$, or UA BE $<-12 \mathrm{mEq} / \mathrm{l}$.

Afterwards, parameters characterizing the course of pregnancy and the newborn's status were correlated with abnormal Doppler results. Additionally, the predictive value of Doppler blood flow indices in relation to fetal and pregnancy outcome determinants was evaluated.

\section{Statistical analysis}

Interval variables such as age, gestational age, body weight, $\mathrm{pH}, \mathrm{pCO}_{2}, \mathrm{pO}_{2}, \mathrm{BE}$ and $\mathrm{C} / \mathrm{U}$ were char- 
acterized by the arithmetic mean and standard deviation. Their normal distribution was verified with the Shapiro-Wilk test. Student's t-test for independent variables was applied to compare the parameters which followed the normal distribution in two groups with equal variances. When in two populations variances were different, Welch's $t$-test was used when two populations variances differed. Data that were not normally distributed were analyzed by the non-parametric Mann-Whitney $U$ test. The group's median, minimum, and maximum values were determined for ordinal variables such as the Apgar score at 1 and $5 \mathrm{~min}$ of life, and to compare two independent groups the non-parametric Mann-Whitney $U$ test was used. For categorical variables, such as the number of newborns in each group and corresponding percentages, contingency tables composed of two parameters were designed. Contingency tables were determined as a composite of two parameters on a nominal scale. To investigate the relation between these parameters, $\chi^{2}$ test with Yates's correction or Fisher's exact test was used. The evaluation was carried out for the following levels of significance: $p<0.05, p<0.01$, $p<0.001$. Additionally, the values of $\mathrm{PI}$ and $\mathrm{RI}$ indices were recoded to normal and abnormal values. These categories constituted a test, and after having analyzed them in terms of parameters characterizing the perinatal outcome, the numbers of true positive, true negative, false positive and false negative cases were consecutively determined. Based on these values it was possible to calculate sensitivity, specificity, and positive and negative predictive values. Statistical analyses were performed using the following statistics packages: Statistica version 8.0 (StatSoft, Inc. 2007), GraphPad InStat (GraphPad Software, Inc.) and Analyse-it for Microsoft Excel v. 2.2 .

\section{Results}

There were no statistically significant differences between the study and the control group in terms of maternal age, gestational age at admission and delivery as well as cesarean section rate. However, the percentage of emergency cesarean sections was significantly higher in the group with BS $(24.6 \%)$ when compared with the control group (7.6\%).

In the study group, the percentage of abnormal CTG records (62.3\%) was significantly higher when compared to controls (19.0\%). A detailed analysis of intrapartum FHR patterns showed statistically significant differences between the study and the control group with regard to the various parameters characterizing CTG (Table I).

The study revealed birth weight, 1- and 5-minute Apgar score, umbilical cord $\mathrm{pH}, \mathrm{BE}, \mathrm{pO}_{2}$, and $\mathrm{pCO}_{2}$ to be significantly lower in patients with $\mathrm{BS}$ when compared to the control group (Table II). Moreover, the prevalence of adverse neonatal outcome and the number of small for gestational age newborns (SGA), values of 1- and 5-minute Apgar score < 7, $\mathrm{pO}_{2}<15 \mathrm{~mm} \mathrm{Hg}, \mathrm{pCO}_{2}>45 \mathrm{~mm} \mathrm{Hg}, \mathrm{pH}$ $<7.2, \mathrm{BE}<-12 \mathrm{mEq} / \mathrm{l}$ and occurrence of MSAF were significantly higher in the study group (Table II). It should be underlined that in the study group there were 3 newborns with $\mathrm{pH}$ equal to or less than 7.0, as well as 3 newborns with a 5-minute Apgar score $<3$.

The comparison of selected Doppler blood flow indices revealed that $\mathrm{C} / \mathrm{U}$ showed the highest sensitivity in prediction of both the intrapartum abnormal FHR (74.1\%) and the adverse neonatal outcome (87.8\%) (Tables III and IV).

\section{Discussion}

The cerebroplacental index, a ratio of MCA RI and UA RI, is widely considered to be more indicative of adverse neonatal outcome than the assessment of blood flow indices individually [10-12]. The C/U assumedly reflects hemodynamic changes and blood flow redistribution more accurately than the umbilical or cerebral flows assessed separately.

Table I. Statistical analysis of CTG patterns in two groups of fetuses: with abnormal vs. normal C/U

\begin{tabular}{|c|c|c|c|c|c|}
\hline \multirow[t]{2}{*}{ Parameter } & \multicolumn{2}{|c|}{ Abnormal C/U $(N=69)$} & \multicolumn{2}{|c|}{ Normal C/U $(N=79)$} & \multirow[t]{2}{*}{ Value of $p^{\mathrm{a}}$} \\
\hline & $n$ & $\%$ & $n$ & $\%$ & \\
\hline Abnormal CTG record & 43 & 62.3 & 15 & 19.0 & $0.0001^{*}$ \\
\hline Fetal bradycardiab & 6 & 8.7 & 3 & 3.8 & NS \\
\hline Fetal tachycardiab & 11 & 15.9 & 4 & 5.1 & NS \\
\hline Late decelerations $^{b}$ & 16 & 23.2 & 1 & 1.3 & $0.0001^{*}$ \\
\hline Variable decelerations ${ }^{b}$ & 21 & 30.4 & 8 & 10.1 & $0.0031^{\star}$ \\
\hline Narrow or silent oscillations ${ }^{b}$ & 18 & 26.1 & 5 & 6.3 & $0.0012^{*}$ \\
\hline
\end{tabular}

CTG - cardiotocographic, C/U - cerebroplacental ratio, $n$ - number, NS - not significant. ${ }^{a} P$-value evaluated with two-sided Fisher's exact

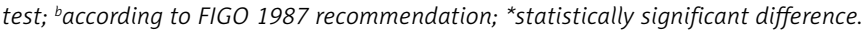


Table II. Statistical analysis of neonatal outcome parameters in two groups: with abnormal vs. normal C/U

\begin{tabular}{|c|c|c|c|}
\hline Neonatal outcome parameters & $\begin{array}{l}\text { Abnormal C/U } \\
\quad(n=69)\end{array}$ & $\begin{array}{c}\text { Normal C/U } \\
\quad(n=79)\end{array}$ & Value of $p^{\text {a }}$ \\
\hline \multicolumn{4}{|l|}{ Birth weight [g]: } \\
\hline Mean \pm standard deviation & $3485 \pm 580$ & $3814 \pm 599$ & \multirow[t]{2}{*}{$0.0009^{*}$} \\
\hline Range & $1730-4470$ & $2760-5130$ & \\
\hline \multicolumn{4}{|l|}{ 1-minute Apgar score: } \\
\hline Median & 7 & 10 & \multirow[t]{3}{*}{$0.0001^{*}$} \\
\hline Range & $0-10$ & $6-10$ & \\
\hline Quartile (Q25-Q75) & $6-10$ & $10-10$ & \\
\hline \multicolumn{4}{|l|}{ 5-minute Apgar score: } \\
\hline Median & 10 & 10 & \multirow[t]{3}{*}{$0.0001^{*}$} \\
\hline Range & $2-10$ & $7-10$ & \\
\hline Quartile (Q25-Q75) & $7-10$ & $10-10$ & \\
\hline \multicolumn{4}{|l|}{$\mathrm{pH}:$} \\
\hline Mean & $7.2 \pm 0.2$ & $7.3 \pm 0.1$ & \multirow[t]{4}{*}{$0.0001^{*}$} \\
\hline Median & 7.26 & 7.34 & \\
\hline Range & $6.80-7.54$ & $7.13-7.46$ & \\
\hline Quartile (Q25-Q75) & $7.14-7.34$ & $7.29-7.37$ & \\
\hline \multicolumn{4}{|l|}{$\mathrm{pO}_{2}[\mathrm{~mm} \mathrm{Hg}]:$} \\
\hline Mean & $17.7 \pm 8.3$ & $22.6 \pm 9.8$ & \multirow[t]{4}{*}{$0.0009^{*}$} \\
\hline Median & 17.0 & 23.0 & \\
\hline Range & $3.0-38.0$ & $2.0-54.0$ & \\
\hline Quartile (Q25-Q75) & $11.0-23.0$ & $17.0-28.0$ & \\
\hline \multicolumn{4}{|l|}{$\mathrm{pCO}_{2}[\mathrm{~mm} \mathrm{Hg}]:$} \\
\hline Mean & $53.0 \pm 17.7$ & $42.9 \pm 8.2$ & \multirow[t]{4}{*}{$0.0001^{*}$} \\
\hline Median & 48.0 & 41.0 & \\
\hline Range & $22.0-109.0$ & $27.0-80.0$ & \\
\hline Quartile (Q25-Q75) & $42.0-60.0$ & $38.0-46.0$ & \\
\hline \multicolumn{4}{|l|}{$\mathrm{BE}[\mathrm{mEq} / \mathrm{l}]:$} \\
\hline Mean & $-7.4 \pm 5.9$ & $-3.7 \pm 3.0$ & \multirow[t]{4}{*}{$0.0001^{*}$} \\
\hline Median & -6.3 & -3.5 & \\
\hline Range & $(-25.0)-(1.2)$ & $(-11.5)-(1.4)$ & \\
\hline Quartile (Q25 - Q75) & $(-10.3)-(-2.9)$ & $(-6.2)-(-1.3)$ & \\
\hline \multicolumn{4}{|l|}{ Adverse neonatal outcome: } \\
\hline$n$ & 35 & 5 & \multirow[t]{2}{*}{$0.0001^{*}$} \\
\hline$\%$ & 50.7 & 6.3 & \\
\hline \multicolumn{4}{|l|}{ Birth weight < 10 percentile: } \\
\hline$n$ & 4 & 0 & \multirow[t]{2}{*}{$0.0450^{*}$} \\
\hline$\%$ & 5.8 & 0.0 & \\
\hline \multicolumn{4}{|l|}{ 1-minute Apgar score < 7 : } \\
\hline$n$ & 39 & 4 & \multirow[t]{2}{*}{$0.0001^{*}$} \\
\hline$\%$ & 56.5 & 5.1 & \\
\hline \multicolumn{4}{|l|}{ 5-minute Apgar score < 7 : } \\
\hline$n$ & 19 & 1 & \multirow[t]{2}{*}{$0.0001^{*}$} \\
\hline$\%$ & 27.5 & 1.3 & \\
\hline \multicolumn{4}{|l|}{$\mathrm{pH}<7,2^{\mathrm{b}}:$} \\
\hline$n$ & 27 & 2 & \multirow[t]{2}{*}{$0.0001^{*}$} \\
\hline$\%$ & 39.1 & 2.5 & \\
\hline
\end{tabular}


Table II. Cont.

\begin{tabular}{|c|c|c|c|}
\hline Neonatal outcome parameters & $\begin{array}{l}\text { Abnormal } C / U \\
(n=69)\end{array}$ & $\begin{array}{l}\text { Normal C/U } \\
(n=79)\end{array}$ & Value of $p^{a}$ \\
\hline \multicolumn{4}{|l|}{$\mathrm{pO}_{2}<15 \mathrm{~mm} \mathrm{Hg}$ : } \\
\hline$n$ & 30 & 19 & \multirow[t]{2}{*}{$0.0145^{*}$} \\
\hline$\%$ & 43.5 & 24.0 & \\
\hline \multicolumn{4}{|l|}{$\mathrm{pCO}_{2}>45 \mathrm{~mm} \mathrm{Hg}:$} \\
\hline$n$ & 31 & 13 & \multirow[t]{2}{*}{$0.0002^{*}$} \\
\hline$\%$ & 44.9 & 16.5 & \\
\hline \multicolumn{4}{|l|}{$\mathrm{BE}<-12 \mathrm{mEq} / \mathrm{l}^{\mathrm{b}}:$} \\
\hline$n$ & 24 & 4 & \multirow[t]{2}{*}{$0.0001^{*}$} \\
\hline$\%$ & 34.8 & 5.1 & \\
\hline \multicolumn{4}{|l|}{ MSAF: } \\
\hline$n$ & 32 & 19 & \multirow[t]{2}{*}{$0.0055^{*}$} \\
\hline$\%$ & 46.4 & 24.1 & \\
\hline
\end{tabular}

$C / U$ - cerebroplacental ratio, $n$ - number, $\mathrm{pO}_{2}$ - oxygen partial pressure, $p \mathrm{CO}_{2}$ - carbon dioxide partial pressure, $B E-b a s e$ excess, $M S A F$

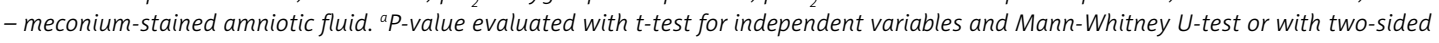
Fisher's exact test; ${ }^{b}$ umbilical cord blood parameters; *statistically significant difference.

Table III. Sensitivity, specificity, positive and negative predictive value and likelihood ratio of Doppler tests in prediction of FHR disturbances (in CTG) at delivery

\begin{tabular}{|c|c|c|c|c|c|c|c|c|c|c|}
\hline & \multirow[t]{2}{*}{ Doppler test } & \multicolumn{2}{|c|}{ Sensitivity } & \multicolumn{2}{|c|}{ Specificity } & \multicolumn{2}{|c|}{ PPV } & \multicolumn{2}{|c|}{ NPV } & \multirow[t]{2}{*}{ LR } \\
\hline & & $\%$ & $95 \% \mathrm{Cl}$ & $\%$ & $95 \% \mathrm{Cl}$ & $\%$ & $95 \% \mathrm{Cl}$ & $\%$ & $95 \% \mathrm{Cl}$ & \\
\hline & $\mathrm{C} / \mathrm{U}$ & 74.1 & $0.61-0.85$ & 71.1 & $0.61-0.80$ & 62.3 & $0.50-0.74$ & 81.0 & $0.71-0.89$ & 2.6 \\
\hline \multirow[t]{4}{*}{ CTG } & MCA RI & 12.0 & $0.05-0.23$ & 91.1 & $0.83-0.96$ & 46.7 & $0.21-0.73$ & 61.6 & $0.53-0.70$ & 1.3 \\
\hline & MCA PI & 56.9 & $0.43-0.70$ & 77.8 & $0.68-0.86$ & 62.3 & $0.48-0.75$ & 73.7 & $0.64-0.82$ & 2.6 \\
\hline & UA RI & 32.8 & $0.21-0.46$ & 87.8 & $0.79-0.94$ & 63.3 & $0.44-0.80$ & 66.9 & $0.58-0.75$ & 2.7 \\
\hline & UA PI & 27.6 & $0.17-0.41$ & 91.1 & $0.83-0.96$ & 66.7 & $0.45-0.84$ & 66.1 & $0.57-0.74$ & 3.1 \\
\hline
\end{tabular}

FHR - fetal heart rate, CTG - cardiotocography, PPV - positive predictive value, NPV - negative predictive value, $L R$ - likelihood ratio, $C I$ - confidence interval, C/U - cerebroplacental ratio, MCA - middle cerebral artery, RI - resistance index, UA - umbilical artery, PI - pulsatility index.

Table IV. Sensitivity, specificity, positive and negative predictive value and likelihood ratio of Doppler tests in prediction of adverse neonatal outcome

\begin{tabular}{|c|c|c|c|c|c|c|c|c|c|c|}
\hline \multirow{7}{*}{$\begin{array}{l}\text { Neonatal } \\
\text { outcome }\end{array}$} & \multirow[t]{2}{*}{ Doppler test } & \multicolumn{2}{|c|}{ Sensitivity } & \multicolumn{2}{|c|}{ Specificity } & \multicolumn{2}{|c|}{ PPV } & \multicolumn{2}{|c|}{ NPV } & \multirow[t]{2}{*}{ LR } \\
\hline & & $\%$ & $95 \% \mathrm{Cl}$ & $\%$ & $95 \% \mathrm{Cl}$ & $\%$ & $95 \% \mathrm{Cl}$ & $\%$ & $95 \% \mathrm{Cl}$ & \\
\hline & $\mathrm{C} / \mathrm{U}$ & 87.8 & $0.74-0.96$ & 68.5 & $0.59-0.77$ & 51.4 & $0.39-0.64$ & 93.7 & $0.86-0.98$ & 2.8 \\
\hline & MCA RI & 17.5 & $0.07-0.33$ & 92.6 & $0.86-0.97$ & 46.7 & $0.21-0.73$ & 75.2 & $0.67-0.82$ & 2.3 \\
\hline & MCA PI & 65.0 & $0.48-0.79$ & 75.0 & $0.66-0.83$ & 49.0 & $0.35-0.63$ & 85.2 & $0.76-0.92$ & 2.6 \\
\hline & UA RI & 40.0 & $0.25-0.57$ & 87.0 & $0.79-0.93$ & 53.3 & $0.34-0.72$ & 79.7 & $0.71-0.87$ & 3.1 \\
\hline & UA PI & 27.5 & $0.15-0.44$ & 88.0 & $0.80-0.93$ & 45.8 & $0.25-0.67$ & 76.6 & $0.68-0.84$ & 2.3 \\
\hline
\end{tabular}

$P P V$ - positive predictive value, NPV - negative predictive value, $L R$ - likelihood ratio, $C l$ - confidence interval, $C / U$-cerebroplacental ratio, $M C A$ - middle cerebral artery, $R I$ - resistance index, UA - umbilical artery, PI - pulsatility index.

In the present study, the percentage of emergency cesarean sections was significantly higher in the group with BS. Moreover, in this group a worse perinatal outcome was observed. Lam et al. assessed a similar relation between $\mathrm{C} / \mathrm{U}$ and the occurrence of MSAF as a diagnostic factor of an adverse perinatal outcome in a homoge- neous group of 118 uncomplicated pregnancies at 41 weeks [13]. They confirmed an association between the rise in vascular resistance in UA and an increased risk of SGA (similarly to the results obtained in the present study), but there was no correlation with the prevalence of MSAF at delivery (in contrast to our results). Lam found MCA PI 
$<10^{\text {th }}$ percentile to be a significant independent predictive factor of MSAF (OR 6.14, Cl: 1.6-24.1; sensitivity $34.2 \%$; specificity $93.7 \%$ ). In Lam's study, $\mathrm{C} / \mathrm{U}<10^{\text {th }}$ percentile correlated with the prevalence of SGA fetuses, but no relation to MSAF incidence was found. However, Lam's study included relatively few pregnancies with MSAF at delivery $(n=26)$, which could have had a considerable impact on the results. Devine et al. obtained contrasting results [14]. They suggested C/U values below 1.05 to be a good predictor of adverse perinatal outcome in post-term pregnancies, but the study included a number of high-risk pregnancies complicated by hypertension or gestational diabetes. In uncomplicated pregnancies without symptoms of abnormal placental function, a decrease in MCA PI values may constitute an early manifestation of adaptive changes even before any alterations in UA appear. At the same time, it may reflect primary changes in vascular resistance appearing in prolonged pregnancies. Habek et al. confirmed the usefulness of $\mathrm{C} / \mathrm{U}$ and fetal biophysical profile assessments in prediction of poor perinatal outcome and impaired neurological development [15-17]. Jain et al. likewise examined the utility of $\mathrm{C} / \mathrm{U}$ as a prognostic factor of adverse perinatal outcome [18]. They found that $a b-$ normal C/U values significantly correlated with fetal distress prevalence, length of stay in the neonatal intensive care unit, and intrauterine growth restriction occurrence. Having compared C/U and UA RI, they stated that the former had higher predictive value with regard to adverse fetal outcome. Yet, it is necessary to note that numerous fetuses included in the study presented signs of intrauterine growth restriction. In addition, different studies revealed that BS as a result of blood redistribution to the brain was significantly related to poor neonatal outcome $[13,15,19]$.

Ott, having examined a heterogeneous group of 447 pregnant women, assessed the accuracy of $\mathrm{C} / \mathrm{U}$ measurements and non-stress test results in prediction of adverse fetal condition [20]. The $\mathrm{C} / \mathrm{U}$ was evaluated based on S/D, and values $<0.1$ were reported as abnormal. Only measurement results obtained within 10 days before delivery were included in the analysis. Adverse neonatal outcome was defined as the presence of intraventricular hemorrhage, anoxic encephalopathy, systemic infection with symptoms of sepsis, necrotizing enterocolitis, or admission to a neonatal intensive care unit. Fetuses with a non-reactive non-stress test and $\mathrm{C} / \mathrm{U}<1.0$ presented the highest percentage of significant complications. Unfortunately, the results are difficult to compare because of the introduced bias due to imprecise criteria of abnormal cardiotocographic records and to heterogeneity of the group, which included uncomplicated pregnancies as well as post-term ones or those complicated by preterm labor or hypertension.
In the current study, a significant increase in prevalence of emergency cesarean sections was noted in the group with C/U ratios < 1.1 (24.6\% vs. $7.6 \%)$. Li et al., having compared the prevalence of operative deliveries performed in pregnancies complicated by fetal distress or not, found no significant differences between the groups in terms of blood flow resistance in MCA [21]. However, it is difficult to compare these studies because of different diagnostic criteria of adverse perinatal outcome.

The $\mathrm{C} / \mathrm{U}$ evaluations are usually interpreted based on a cut-off value. Values $<1.08$ were reported to be abnormal [11]. Some authors suggest that reference ranges should be applied for C/U assessment [10, 22]. However, there are studies which revealed no superiority of reference ranges over cut-off values with regard to adverse perinatal outcome prediction [23].

Palacio et al. put forward suggestions for new reference ranges for $\mathrm{UA} \mathrm{PI}, \mathrm{MCA} \mathrm{PI}$ and $\mathrm{C} / \mathrm{U}$, with particular emphasis on the period between 41 and $42+6$ weeks of gestation [24]. Their normal ranges for MCA PI are much wider than those presented previously. The proper classification of PI values as normal or abnormal is crucial. Researchers have frequently postulated that these are probably processes of obsolescence of the placenta and its consequent insufficiency occurring in prolonged pregnancies that lead to increased perinatal mortality and morbidity. Thus, one would expect changes that are typical for intrauterine growth restriction to appear in prolonged gestations. However, the research of Palacio et al. revealed no increase in the value of UA PI in uncomplicated prolonged pregnancies and suggested that the vascular resistance does not rise during this period [24].

It is widely believed that $\mathrm{C} / \mathrm{U}$ is the blood flow index that best illustrates the phenomenon of blood redistribution to the brain. A decline in $\mathrm{C} / \mathrm{U}$ values can either result from the rise in vascular resistance in $\mathrm{UA}$, which reflects the placental resistance changes, or be a consequence of the BS effect arising from the fall in cerebral vascular resistance [10]. Gramellini, as well as other researchers, reported that $C / U$ values are constant throughout the last ten weeks of pregnancy. That is why the value of 1.08 was established as a cutoff point and values $<1.08$ (which is 2 SDs below the mean) were reported as abnormal [11]. Devine et al. claimed that $\mathrm{C} / \mathrm{U}$ of less than 1.05 was the best predictor of adverse perinatal outcome [14]. However, some authors, including Palacio et al., have stated that although the mean $\mathrm{C} / \mathrm{U}$ is relatively constant in post-term gestation, the $5^{\text {th }}$ percentile still decreases as a consequence of SD's increasing trend (which resulted in a progressively wider $90 \%$ normality range) [24]. It was suggested that referring to normal ranges may have higher 
predictive value in determining fetuses at risk of complications, rather than single cut-off values. In the opinion of the above-mentioned authors, the use of $\mathrm{C} / \mathrm{U}$ to monitor fetal condition in postterm pregnancies as well as its superiority over UA PI and MCA PI assessed separately remains controversial.

In conclusion, the $\mathrm{C} / \mathrm{U}$ index shows the highest sensitivity in prediction of FHR abnormalities and adverse neonatal outcome in uncomplicated pregnancies at 40 weeks and beyond. The $C / U$ index is useful in clinical practice in antenatal monitoring of these women in order to select those at high risk of intra- and postpartum complications.

\section{Acknowledgments}

Thanks to Lucyna Kramer PhD for methodological support.

\section{Conflict of interest}

The authors declare no conflict of interest.

\section{References}

1. Korbelak T, Ropacka-Lesiak M, Bręborowicz G. Doppler blood flow velocimetry in the umbilical artery in uncomplicated pregnancy [Polish]. Ginekol Pol 2012; 83: 38-45.

2. Ropacka-Lesiak M, Korbelak T, Bręborowicz G. Hypoxia index in the prediction of abnormal CTG at delivery in uncomplicated pregnancies. Neuroendocrinol Lett 2012; 33: 5-9.

3. Salihagić-Kadić A, Medić M, Jugović D, et al. Fetal cerebrovascular response to chronic hypoxia-implications for the prevention of brain damage. J Matern Fetal Neonatal Med 2006; 19: 387-96.

4. Johnston MV, Trescher WH, Ishida A, Nakajima W. Neurobiology of hypoxic-ischemic injury in the developing brain. Pediatr Res 2001; 49: 735-41.

5. Schreuder AM, McDonnell M, Gaffney G, et al. Outcome at school age following antenatal detection of absent or reversed end diastolic flow in the umbilical artery. Arch Dis Child Fetal Neonatal Ed 2002; 86: F108-14.

6. Brar HS, Horenstein J, Medearis AL, et al. Cerebral, umbilical, and uterine resistance using Doppler velocimetry in postterm pregnancy. J Ultrasound Med 1989; 8: 187-91.

7. Arbeille P, Perrotin F, Salihagić A, et al. Fetal Doppler hypoxic index for the prediction of abnormal fetal heart rate at delivery in chronic fetal distress. Eur J Obstet Gynecol Reprod Biol 2005; 121: 171-7.

8. Scherjon S, Briet J, Oosting H, Kok J. The discrepancy between maturation of visual-evoked potentials and cognitive outcome at five years in very preterm infants with and without hemodynamic signs of fetal brain-sparing. Pediatrics 2000; 105: 385-91.

9. Rooth G. Guidelines for the use of fetal monitoring FIGO News. Int J Gynecol Obstet 1987; 25: 159-67.

10. Baschat AA, Gembruch U. The cerebroplacental Doppler ratio revisited. Ultrasound Obstet Gynecol 2003; 21: 124-7.

11. Gramellini D, Folli MC, Raboni S. Cerebral-umbilical Doppler ratio as a predictor of adverse perinatal outcome. Obstet Gynecol 1992; 79: 416-20.
12. Hershkovitz R, Kingdom JCP, Geary M, Rodeck CH. Fetal cerebral blood flow redistribution in late gestation: identification of compromise in small fetuses with normal umbilical artery Doppler. Ultrasound Obstet Gynecol 2000; 15: 209-12.

13. Lam H, Leung WC, Lee CP, Lao TT. The use of fetal Doppler cerebroplacental blood flow and amniotic fluid volume measurement in the surveillance of postdated pregnancies. Acta Obstet Gynecol Scand 2005; 84: 844-8.

14. Devine PA, Bracero LA, Lysikiewicz A, et al. Middle cerebral to umbilical artery Doppler ratio in post-date pregnancies. Obstet Gynecol 1994; 84: 856-60.

15. Habek D, Salihagić A, Jugović D, Herman R. Doppler cerebro-umbilical ratio and fetal biophysical profile in the assessment of peripartal cardiotocography in growth-retarded fetuses. Fetal Diagn Ther 2007; 22: 452-6.

16. Habek D, Hodek B, Herman R, et al. Fetal biophysical profile and cerebro-umbilical ratio in assessment of perinatal outcome in growth-restricted fetuses. Fetal Diagn Ther 2003; 18: 12-6.

17. Habek D, Jugović D, Hodek B, et al. Fetal biophysical profile and cerebro-umbilical ratio in assessment of brain damage in growth restricted fetuses. Eur J Obstet Gynecol Reprod Biol 2004; 114: 29-34.

18. Jain M, Farooq T, Shukla RC. Doppler cerebroplacental ratio for the prediction of adverse perinatal outcome. Int J Gynaecol Obstet 2004; 86: 384-5.

19. Ropacka-Lesiak M, Korbelak T, Bręborowicz GH. Doppler blood flow velocimetry in the middle cerebral artery in uncomplicated pregnancy [Polish]. Ginekol Pol 2011; 82 185-90.

20. Ott WJ. Comparison of the non-stress test with the evaluation of centralization of blood flow for the prediction of neonatal compromise. Ultrasound Obstet Gynecol 1999; 14: 38-41.

21. Li H, Gudmundsson S, Olofsson P. Acute centralization of blood flow in compromised human fetuses evoked by uterine contractions. Early Hum Dev 2006; 82: 747-52.

22. Ebbing C, Rasmussen S, Kiserud T. Middle cerebral artery blood flow velocities and pulsatility index and the cerebroplacental pulsatility ratio: longitudinal reference ranges and terms for serial measurements. Ultrasound Obstet Gynecol 2007; 30: 287-96.

23. Odibo AO, Riddick C, Pare E, et al. Cerebroplacental Doppler ratio and adverse perinatal outcomes in intrauterine growth restriction: evaluating the impact of using gestational age-specific reference values. J Ultrasound Med 2005; 24: 1223-8.

24. Palacio M, Figueras F, Zamora L, et al. Reference ranges for umbilical and middle cerebral artery pulsatility index and cerebroplacental ratio in prolonged pregnancies. Ultrasound Obstet Gynecol 2004; 24: 647-53. 